\title{
Prepubertal onset of slipped capital femoral epiphysis associated with hypothyroidism: a case report and literature review
}

\author{
Saori Kadowaki ${ }^{1}$, Tomohiro Hori ${ }^{1 *}$ (D), Hideki Matsumoto ${ }^{1}$, Kaori Kanda ${ }^{1}$, Michio Ozeki $^{1}$, Yu Shirakami ${ }^{2}$,
} Norio Kawamoto', Hidenori Ohnishi ${ }^{1}$ and Toshiyuki Fukao ${ }^{1}$

\begin{abstract}
Background: Slipped capital femoral epiphysis (SCFE) is a common hip disorder characterized by displacement of the capital femoral epiphysis from the metaphysic through the femoral epiphyseal plate. SCFE usually occurs during puberty, with obesity a common risk factor. We experienced a rare case of SCFE associated with hypothyroidism in a prepubescent patient who was not obese.

Case presentation: The patient was an 8-year-old boy suffering from bilateral SCFE with hypothyroidism. The patient's growth had started to slow at 4 years of age, and at 8 years he was of short stature. During his evaluation for SCFE management, primary hypothyroidism was diagnosed due to the presence of anti-thyroid peroxidase and anti-thyroglobulin antibodies. After the patient was treated for hypothyroidism, which improved his thyroid function, surgery was performed for bilateral SCFE.

Conclusions: Among the 42 patients with SCFE associated with hypothyroidism in the literature, most SCFE occurred during puberty or in adults with delayed epiphyseal closure. Only two patients (4.8\%), including the present patient, were $\leq 9$ years old. Although being overweight or obese is common for patients with SCFE associated with hypothyroidism (76.0\%), it was not observed in the present case. Persistent hypothyroidism, however, may be a risk factor for SCFE even before puberty and without obesity.
\end{abstract}

Keywords: Atrophic thyroiditis, Endocrinology, Hypothyroidism, Pediatrics, Slipped capital femoral epiphysis

\section{Background}

Slipped capital femoral epiphysis (SCFE) is defined as posterior and inferior slippage of the proximal femoral epiphysis on the metaphysis (femoral neck), which occurs through the epiphyseal plate (growth plate) [1, 2]. SCFE, a rare disease, is known to be strongly associated with obesity. Most patients develop SCFE during puberty. The majority of SCFE cases are idiopathic, although, atypically, SCFEs may be due to an endocrine disorder, renal failure, osteodystrophy, or radiation therapy. The current incidence of SCFE in children 8-

\footnotetext{
*Correspondence: hori-gif@umin.org

'Department of Pediatrics, Graduate School of Medicine, Gifu University, 1-1 Yanagido, Gifu, Gifu 501-1194, Japan

Full list of author information is available at the end of the article
}

15 years of age ranges from $0.33 / 100,000$ to 24.58/ 100,000, depending on sex and ethnicity [3]. From 1976 to 2002 in Japan, the incidence of SCFE in those 1014 years of age increased from a range of $0.3-0.5$ to $2.22 / 100,000$ in boys and from $0.05-0.08$ to 0.76 in girls [4]. Thus, the incidence has increased approximately 5 fold in boys and 10-fold in girls, bringing it closer to the figures in other countries. The main cause for the increased numbers of SCFE in Japanese children is thought to be obesity.

Rarely, SCFE is an important complication of hypothyroidism that often develops during childhood. We describe a case of hypothyroidism accompanied by SCFE in a prepubertal patient. We also review previously reported cases of SCFE associated with hypothyroidism. 


\section{Case presentation}

An 8-year-old boy presented with pain in his left hip joint that had persisted for several months. His height was $112.5 \mathrm{~cm}$ (-2.93 standard deviation), and his weight was $21.5 \mathrm{~kg}$, from which body mass index was calculated to 67.1 percentile for age and sex. His growth had started to slow at 4 years of age (Fig. 1). He presented with hirsutism, dry skin, and bradycardia. Hip joint radiography revealed Trethowan's sign bilaterally in the frontal view and a posterior tilting angle of $34^{\circ}$ on the left side and $25^{\circ}$ on the right side in the Lauenstein view (Fig. 2). Magnetic resonance imaging (MRI) of the hip joint showed separation of the proximal metaphysis of the femur. Based on these findings, the patient was diagnosed with chronic bilateral SCFE (mild on the right side, moderate on the left side).

Blood tests revealed hepatic dysfunction and hypercholesterolemia, with a very low free thyroxine level of $0.10 \mathrm{ng} / \mathrm{dl}$ and a very high thyroid-stimulating hormone (TSH) level of $1789 \mu \mathrm{IU} / \mathrm{ml}$. The anti-thyroid peroxidase antibody level was $>600 \mathrm{IU} / \mathrm{ml}$, and the anti-thyroglobulin antibody level was $1720 \mathrm{IU} / \mathrm{ml}$. At the age of 8 years 7 months, the bone age (assessed by the Tanner-Whitehouse 2 radius, ulna, short bones method) was 3 years 4 months. Ultrasonography showed marked atrophy of

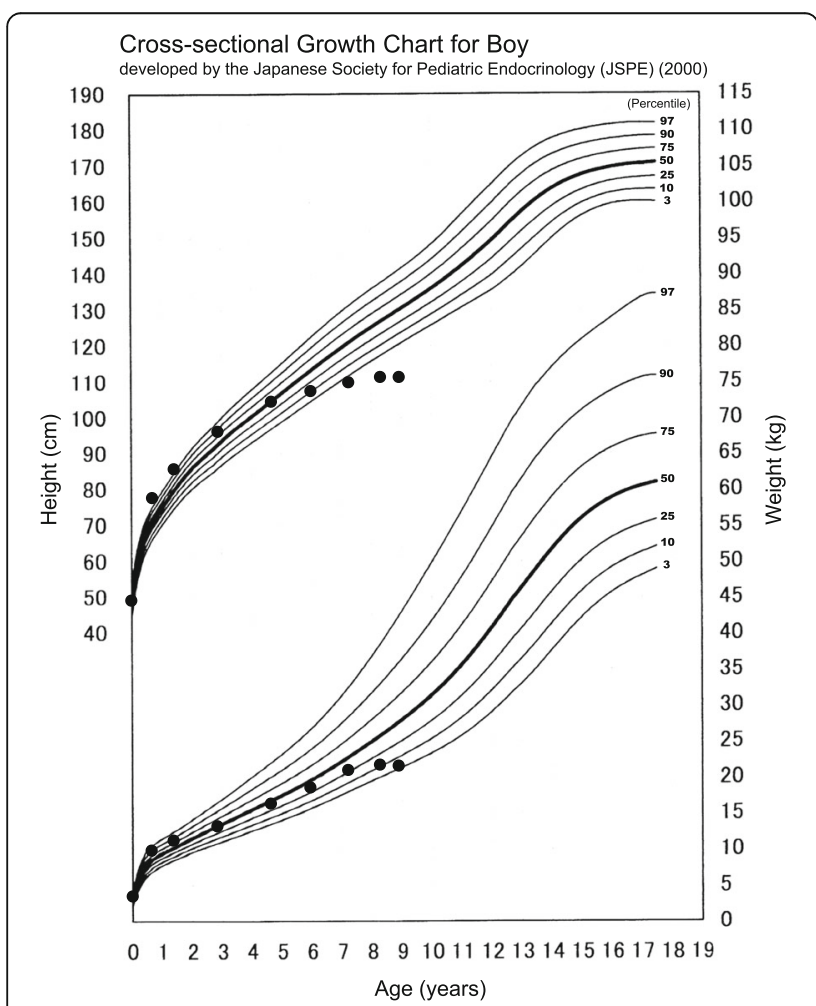

Fig. 1 Growth chart for the patient. Serial height and weight measurements of the patient were plotted using the standard growth chart (developed by the Japanese Society for Pediatric Endocrinology)

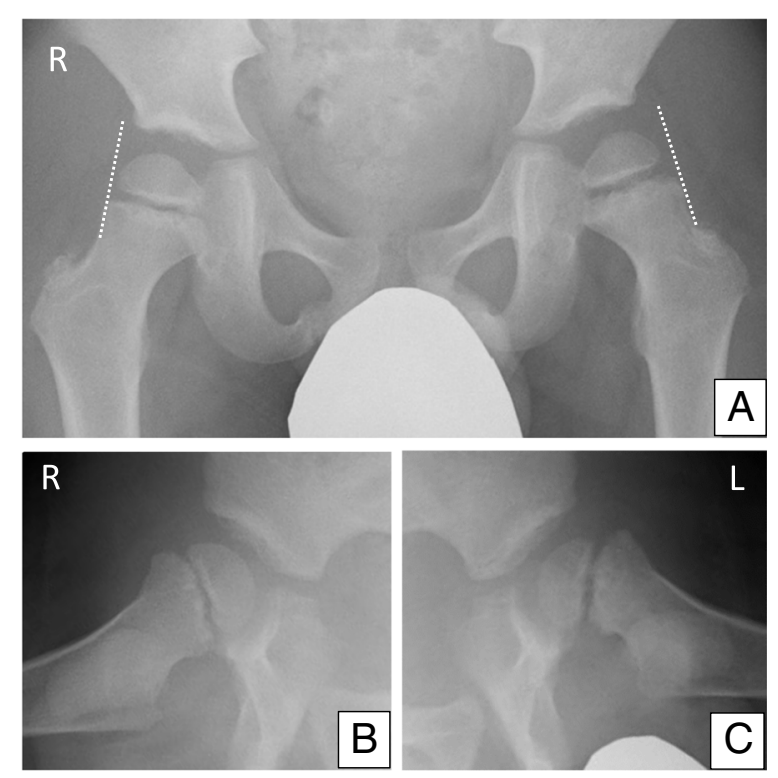

Fig. 2 Radiological findings of the patient. Radiographs of the hip joint show Trethowan's sign bilaterally in the frontal view (a) and a posterior tilting angle of $25^{\circ}$ on the right side (b) and $34^{\circ}$ on the left side (c) in the Lauenstein view

the thyroid, and color-flow Doppler sonography revealed decreased thyroid blood flow. Cardiac ultrasonography disclosed slight retention of pericardial fluid. MRI scans of the head showed that the anterior lobe of the pituitary gland was enlarged to a height of $17 \mathrm{~mm}$. Although the pituitary gland displaced the optic chiasm superiorly, there were no visual acuity or field abnormalities. Hyperplasia of the anterior lobe of the pituitary gland caused by the overproduction of TSH was suspected. Therefore, atrophic thyroiditis was diagnosed.

For SCFE treatment, the patient was admitted and kept at rest, with the lower limbs in traction. Oral levothyroxine therapy was initiated with a low dose, followed by gradual dose increases. About 2 months later, the free thyroxine levels had increased to the normal range. In addition, the hirsutism, dry skin, and bradycardia had diminished, and his growth velocity had improved. MRI scans of the head showed reduction of the swollen pituitary gland. An arginine stimulation test $(0.5 \mathrm{~g} / \mathrm{kg}$ infused intravenously over $30 \mathrm{~min})$ showed a normal growth hormone response (peak $7.26 \mathrm{ng} / \mathrm{ml}$ ). Also, a human corticotropin-releasing hormone stimulation test $(1.5 \mu \mathrm{g} / \mathrm{kg}$ infused intravenously) showed a normal adrenocorticotropic hormone response (peak $48.4 \mathrm{pg} / \mathrm{ml}$ ) and cortisol response (peak $14.4 \mu \mathrm{g} / \mathrm{dl}$ ). After 2 months of thyroxine treatment, the patient's thyroid levels had stabilized, at which time surgery was performed for bilateral SCFE.

The CARE guidelines were followed in this case. 
Table 1 Reported cases of SCFE associated with hypothyroidism

\begin{tabular}{|c|c|c|c|c|}
\hline $\begin{array}{l}\text { Publication year } \\
\text { [reference] }\end{array}$ & Age/Sex & Height $^{\mathrm{b}}$ & Weight $^{\mathrm{a}}$ & Diseased side \\
\hline 2004 [5] & $7 / M$ & short stature & obese or overweight & bilateral \\
\hline Present case ${ }^{c}$ & $8 / \mathrm{M}$ & short stature & normal body weight & bilateral \\
\hline $1984[6]$ & $10 / F$ & N/A & $\mathrm{N} / \mathrm{A}$ & right \\
\hline 2010 [7] & $10 / F$ & N/A & obese & bilateral \\
\hline 1984 [6] & $11 / \mathrm{M}$ & short stature & $\mathrm{N} / \mathrm{A}$ & bilateral \\
\hline 2004 [5] & $11 / F$ & short stature & obese or overweight & unilateral \\
\hline 2004 [5] & $11 / F$ & short stature & obese or overweight & unilateral \\
\hline $1993[8]$ & $11 / F$ & normal stature & overweight & left \\
\hline 2004 [5] & $12 / \mathrm{M}$ & short stature & obese or overweight & bilateral \\
\hline 2004 [5] & $12 / \mathrm{M}$ & short stature & obese or overweight & unilateral \\
\hline $1993[8]$ & $12 / \mathrm{M}$ & normal stature & obese & left \\
\hline $2008[9]$ & $12 / \mathrm{M}$ & N/A & obese & bilateral \\
\hline $2016[10]$ & $12 / \mathrm{M}$ & normal stature & overweight & right \\
\hline 2004 [5] & $12 / F$ & short stature & obese or overweight & bilateral \\
\hline $1993[8]$ & $12 / F$ & normal stature & obese & right \\
\hline 1980 [11] & $12 / F$ & N/A & $\mathrm{N} / \mathrm{A}$ & bilateral \\
\hline 1980 [12] & $12 / F$ & short stature & $\mathrm{N} / \mathrm{A}$ & left \\
\hline $1985[13]^{c}$ & $12 / F$ & short stature & obese & left \\
\hline 2002 [14] & $12 / F$ & N/A & $\mathrm{N} / \mathrm{A}$ & right \\
\hline 2014 [15] & $12 / F$ & short stature & overweight & left \\
\hline 1984 [6] & $13 / \mathrm{M}$ & N/A & N/A & bilateral \\
\hline 1984 [6] & $13 / \mathrm{M}$ & N/A & N/A & left \\
\hline 1984 [6] & $13 / \mathrm{M}$ & short stature & $\mathrm{N} / \mathrm{A}$ & bilateral \\
\hline $1992[16]^{c}$ & $13 / \mathrm{M}$ & N/A & $\mathrm{N} / \mathrm{A}$ & left \\
\hline $2013[17]$ & $13 / \mathrm{M}$ & short stature & $\mathrm{N} / \mathrm{A}$ & bilateral \\
\hline $2016[18]$ & $13 / \mathrm{M}$ & short stature & $\mathrm{N} / \mathrm{A}$ & bilateral \\
\hline 1984 [6] & $13 / F$ & short stature & N/A & left \\
\hline 1984 [6] & $13 / F$ & N/A & $\mathrm{N} / \mathrm{A}$ & right \\
\hline $2001[19]^{c}$ & $13 / F$ & N/A & N/A & right \\
\hline 2010 [20] & $13 / F$ & short stature & normal body weight & left \\
\hline 2013 [21] & $14 / \mathrm{M}$ & short stature & obese & right \\
\hline 1980 [12] & $14 / F$ & short stature & N/A & left \\
\hline 1994 [22] & $14 / F$ & short stature & normal body weight & right \\
\hline $2016[10]$ & $15 / \mathrm{M}$ & short stature & obese & left \\
\hline 2007 [23] & $15 / \mathrm{M}$ & short stature & $\mathrm{N} / \mathrm{A}$ & right \\
\hline $1993[8]$ & $15 / F$ & short stature & overweight & right \\
\hline 2016 [18] & $17 / \mathrm{M}$ & N/A & obese & bilateral \\
\hline $1988[24]^{c}$ & $18 / F$ & short stature & overweight & left \\
\hline $2010[25]$ & $19 / \mathrm{M}$ & normal stature & normal body weight & left \\
\hline 1982 [26] & $21 / \mathrm{M}$ & normal stature & normal body weight & right \\
\hline $2008[27]$ & $24 / F$ & short stature & normal body weight & bilateral \\
\hline 2014 [28] & $28 / F$ & short stature & N/A & right \\
\hline
\end{tabular}

$M$ male, $F$ female, $N / A$ not available

according to growth charts developed by the National Center for Health Statistics in collaboration with the National Center for Chronic Disease Prevention and Health Promotion (http://www.cdc.gov/growthcharts, published in 2000, accessed $1 \mathrm{Sep}$. 2016), the 85th-95th body mass index (BMI) percentiles for age and sex were defined as overweight and $\geq 95$ th percentile as obese. Among patients aged 18 years or older, a BMI of 25 or more was defined as overweight, and a BMI of 30 or more as obese bhort stature was defined as $\leq 3$ rd percentile

'Growth charts for Japanese individuals developed by the Japanese Society for Pediatric Endocrinology (http://jspe.umin.jp/medical/taikaku.html, published in 2000, accessed 1 Sep. 2016) was used for analysis in Japanese patients 


\section{Discussion and conclusions}

We describe herein an 8-year-old patient with bilateral SCFE. He was diagnosed with hypothyroidism during the examination for possible SCFE after 4 years of slow growth. We also reviewed the literature for other cases of SCFE with hypothyroidism versus those with SCFE alone.

An epidemiological study of 314 patients with SCFE in Japan showed that most cases occurred during adolescence. Only seven patients had developed SCFE after the age of 20 years, and around one in every eight SCFE cases occurred before the age of 9 years. Endocrine abnormality was present in only 3 of 307 patients $<20$ years of age, whereas all 7 patients aged $\geq 20$ years had an endocrine disease [4]. The proximal epiphysis of the femur generally closes between 15 and 17 years of age, after which SCFE does not occur. If epiphyseal closure is delayed because of the influence of an endocrine disease (e.g., hypothyroidism, hypogonadism), however, SCFE may occur even during adulthood. Hence, it is widely recognized that endocrine disease should be taken into consideration in cases of adulthood SCFE.

In addition to our current case, we reviewed the clinical features of 42 cases of SCFE with hypothyroidism from 24 reports published after 1980 (Table 1) [5-28]. The age of onset ranged from 7 to 28 years (mean 13.5 years, median 13 years). The onset of SCFE with hypothyroidism was commonly during adolescence. Accordingly, five patients $(11.9 \%)$ had disease onset at $\geq 18$ years. Only two patients $(4.8 \%)$, including our own, had disease onset at $\leq 9$ years of age. Thus, our case is a rare example of SCFE with hypothyroidism occurring prior to puberty.

We assessed the relation between the patient's body weight and SCFE. It has been reported that SCFE patients with an age-specific body mass index in the $\geq 95$ th percentile accounted for $76.3 \%$ of cases, and those in the $\geq 85$ th percentile accounted for $92.5 \%$ of cases [29]. These data indicate that obesity is a risk factor for SCFE. As shown in Table 1, among the 42 patients with SCFE and hypothyroidism, body weight data were available for only 25 , of whom 19 were obese or overweight (76.0\%) (defined according to growth charts of the National Center for Health Statistics and National Center for Chronic Disease Prevention and Health Promotion) (Table 1). It is possible that myxedema contributed to their increased weight. These facts suggest that obesity is also a risk factor for SCFE with hypothyroidism. Our patient was not overweight, however, and so represents a rare example of SCFE with hypothyroidism from the viewpoint of body weight. It could also be presumed that the reports for the remaining 17 of the 42 patients did not refer to weight because the body weight of these individuals was proportional to their height. If this supposition is correct, non-obese patients would account for a relatively large proportion of those with SCFE associated with hypothyroidism.

Among the 42 patients with SCFE with hypothyroidism (Table 1), height was reported for 31. Short stature was seen in 25 patients $(80.6 \%$ ) (defined according to the growth charts referenced in Table 1), and 6 were of normal height. Because hypothyroidism during childhood inhibits growth, short stature indicates that hypothyroidism persists for several years before the induction of SCFE. Our patient presented with a 4-year period of reduced growth (Fig. 1). Persistent hypothyroidism may contribute to the development of SCFE.

The etiology of SCFE is poorly understood. In general, it is thought to develop in the presence of increased shearing force on the proximal epiphysis of the femur caused by obesity when growth hormones dominate over sex hormones during puberty [30]. Alternatively, thyroid hormone deficiency in children causes a delay in endochondral and intramembranous ossification and hypoplasia of the epiphyseal plate (growth plate). Thyroid hormone deficiency also induces inactivation of the growth hormone/insulin-like growth factor axis [31]. The effect of hypothyroidism on the growth plate has been observed in recent animal experiments in which swine suffering from hypothyroidism exhibited significantly decreased gene expression of proteoglycans and type X collagen. Such changes likely weaken overall epiphyseal strength and resilience, which could provide an insight into human orthopedic growth plate pathologies [32]. Moyer et al. [18] recommended that thyroid function screening be conducted in patients suffering from SCFE with an atypical presentation, which could include those presenting at $<10$ or $>16$ years of age, those with bilateral SCFE, and/or those whose height is $\leq 10 \%$ of normal for age and sex. In our patient, SCFE was triggered by prepubertal hypothyroidism, suggesting that hypothyroidism should be recognized as an independent risk factor for the development of SCFE.

In conclusion, thyroid function should be closely evaluated in patients with SCFE, especially those who are prepubescent, not obese, have a short stature for age and sex, and/or exhibit reduced growth.

\section{Abbreviations \\ MRI: Magnetic resonance imaging; SCFE: Slipped capital femoral epiphysis; TSH: Thyroid-stimulating hormone}

\section{Acknowledgements}

The authors thank the patient and his family for their participation. We thank Nancy Schatken, BS, MT(ASCP), from Edanz Group (www.edanzediting.com/ ac) for editing a draft of this manuscript.

\section{Funding}

This research did not receive any grants from any funding agencies.

Availability of data and materials

All data generated or analyzed during this study are included in this published article. 


\section{Authors' contributions}

SK, TH, HM, KK, MO, and YS diagnosed the patient, performed investigations and follow-up, and drafted the manuscript. NK, HO, and TF analyzed the data and critically revised the manuscript. SK and TH reviewed the literature, drafted the manuscript, and reviewed the manuscript for final publication. All authors read and approved the final manuscript.

\section{Authors' information}

${ }^{1} \mathrm{SK}, \mathrm{TH}, \mathrm{HM}, \mathrm{KK}, \mathrm{MO}, \mathrm{NK}, \mathrm{HO}$ and TF; Department of Pediatrics, Graduate School of Medicine, Gifu University, 1-1 Yanagido, Gifu, Gifu 501-1194, Japan. ${ }^{2}$ YS; Department of Pediatrics, Kibogaoka Medical and Support Center for Children, Gifu, Gifu, Japan.

\section{Ethics approval and consent to participate}

This study was performed according to the Helsinki Declaration. Written informed consent to include her child in the study was obtained from the patient's mother.

\section{Consent for publication}

Written informed consent was obtained from the patient's mother for publication of the details of the case report.

\section{Competing interests}

The authors declare that they have no competing interests.

\section{Publisher's Note}

Springer Nature remains neutral with regard to jurisdictional claims in published maps and institutional affiliations.

\section{Author details}

'Department of Pediatrics, Graduate School of Medicine, Gifu University, 1-1 Yanagido, Gifu, Gifu 501-1194, Japan. ²Department of Pediatrics, Kibogaoka Medical and Support Center for Children, 1816-1 Noritake, Gifu, Gifu 502-0931, Japan.

Received: 31 May 2017 Accepted: 12 September 2017

Published online: 18 September 2017

\section{References}

1. Peck D. Slipped capital femoral epiphysis: diagnosis and management. Am Fam Physician. 2010;82:258-62.

2. Gholve PA, Cameron DB, Millis MB. Slipped capital femoral epiphysis update. Curr Opin Pediatr. 2009;21:39-45.

3. Loder RT, Skopelja EN. The epidemiology and demographics of slipped capital femoral epiphysis. ISRN Orthop. 2011;2011:486512

4. Noguchi Y, Sakamaki T. Multicenter Sutdy Commitee of the Japanese pediatric Orthopaedic association. Epidemiology and demographics of slipped capital femoral epiphysis in Japan: a multicenter study by the Japanese Paediatric Orthopaedic Association J Orthop Sci. 2002;7:610-7.

5. Bosch P, Johnston CE, Karol L. Slipped capital femoral epiphysis in patients with down syndrome. J Pediatr Orthop. 2004;24:271-7.

6. Heyerman W, Weiner D. Slipped epiphysis associated with hypothyroidism. I Pediatr Orthop. 1984:4:569-73.

7. Azzopardi T, Sharma S, Bennet GC. Slipped capital femoral epiphysis in children aged less than 10 years. J Pediatr Orthop B. 2010;19:13-8.

8. Wells D, King JD, Roe TF, Kaufman FR. Review of slipped capital femoral epiphysis associated with endocrine disease. J Pediatr Orthop. 1993:13:610-4.

9. Lim YJ, Lam KS, Lee EH. Review of the management outcome of slipped capital femoral epiphysis and the role of prophylactic contra-lateral pinning re-examined. Ann Acad Med Singap. 2008;37:184-7.

10. Tang S, Xin Y. Hypothyroidism with slipped capital femoral epiphysis. Indian Pediatr. 2016:83:750-1.

11. Fisher M, Frogel M, Raifman MA, Nussbaum M. Hypothyroidism and slipped capital femoral epiphysis. J Pediatr. 1980:96:517-8.

12. Jayakumar S. Slipped capital femoral epiphysis with hypothyroidism treated by nonoperative method. Clin Orthop Relat Res. 1980;151:179-82.

13. Nishi Y, Masuda H, Iwamori H, Urabe T, Sakoda K, Uozumi T, et al. Primary hypothyroidism associated with pituitary enlargement, slipped capital femoral epiphysis and cystic ovaries. Eur J Pediatr. 1985;143:216-9.
14. Sanders JO, Smith WJ, Stanley EA, Bueche MJ, Karol LA, Chambers HG Progressive slippage after pinning for slipped capital femoral epiphysis. J Pediatr Orthop. 2002;22:239-43.

15. Uday S, Scott B, Alvi S. Hashimoto's hypothyroidism presenting with SUFE (slipped upper femoral epiphysis). BMJ Case Rep. 2014;2014:bcr2013203095.

16. Chiba K, Fujita H, Kimura Y, Otsuka M, Echizennya T, Sekiue I. A case of primary hypothyroidism with pituitary enlargement, slipped capital femoral epiphysis and diabetes mellitus, experience of the growth hormone dosage for the growth hormone deficiency after recovering normal thyroid function. Nihon Syonika Gakkai zassi. 1992;96:658. (in Japanese)

17. Walter RP, Jeffery RS, Holroyd B. Bilateral epiphyseal migration following fixation for slipped capital femoral epiphyses in a hypothyroid child. Acta Orthop Belg. 2013;79:235-8.

18. Moyer J, Jacks L, Hunter JD, Chan G. Slipped capital femoral epiphysis and associated hypothyroidism. A review of the literature with two classic case examples. J Pediatr Endocrinol Metab. 2016;29:427-34.

19. Ohmori M, Harada K, Kobayashi E, Fujimura A. A case of the hypothyroidism found for slipped capital femoral epiphysis. Naika. 2001;87:787. (in Japanese)

20. Abaci A, Taşcilar ME, Ugurel MS, Yesilkaya E, Coskun ZÜ, Yildiz C. Osteopetrosis and congenital hypothyroidism complicated by slipped capital femoral epiphysis. Endocr Pract. 2010;16:646-9.

21. Hutchins KL. Slipped capital femoral epiphysis and hypothyroidism in a patient with down syndrome. JAAPA. 2013;26:35-7.

22. Guiral J, Fisac R, Martin-Herraez A, Garcia-Velazquez J. Slipped capital femoral epiphysis in primary juvenile hypothyroidism. Acta Orthop Belg. 1994;60:343-5

23. Jacob J, Paul T. A boy with a limp. Slipped capital femoral epiphysis N Z Med J. 2007:120:U2447.

24. Chosa E, Nagashima Y, Hirakawa S, Nakamura S, Yano T. A case of slipped femoral epiphysis complicated with hypothyroidism. Seikeigeka. 1988;39: 952-5. (in Japanese)

25. Koteles MR Jr, Lewi JE. Visual vignette. Slipped capital femoral epiphysis (SCFE) attributable to primary hypothyroidism. Endocr Pract. 2010;16:340.

26. Hennessy MJ, Jones KL. Slipped capital femoral epiphysis in a hypothyroid adult male. Clin Orthop Relat Res. 1982;165:204-8.

27. Nourbakhsh A, Ahmed HA, McAuliffe TB, Garges KJ. Case report: bilateral slipped capital femoral epiphyses and hormone replacement. Clin Orthop Relat Res. 2008;466:743-8.

28. Marquez D, Harb E, Vilchis H. Slipped capital femoral epiphysis and hypothyroidism in a young adult: a case report. J Med Case Rep. 2014;10:336.

29. Aversano MW, Moazzaz P, Scaduto AA, Otsuka NY. Association between body mass index-for-age and slipped capital femoral epiphysis: the longterm risk for subsequent slip in patients followed until physeal closure. J Child Orthop. 2016:10:209-13.

30. Harris R. The endocrine basis of slipping of the upper femoral epiphysis; an experimental study. J Bone Joint Surg. 1950:32-B:5-11.

31. Yen PM. Physiological and molecular basis of thyroid hormone action. Physiol Rev. 2001;81:1097-142.

32. Tank JC, Weiner DS, Jacquet R, Childs D, Ritzman TF, Horne Wl, et al. The effects of hypothyroidism on the proximal femoral physis in miniature swine. J Orthop Res. 2013;31:1986-91.

\section{Submit your next manuscript to BioMed Central and we will help you at every step:}

- We accept pre-submission inquiries

- Our selector tool helps you to find the most relevant journal

- We provide round the clock customer support

- Convenient online submission

- Thorough peer review

- Inclusion in PubMed and all major indexing services

- Maximum visibility for your research

Submit your manuscript at www.biomedcentral.com/submit
Biomed Central 